\title{
A CONCEPÇÃO DE NATUREZA NA GEOGRAFIA
}

\author{
Msc. Kalina Salaib Springer \\ Doutoranda no Programa de Pós-Graduação em Geografia, Instituto de Geociências, UNICAMP. \\ Rua João Pandiá Calógeras, 51 - CEP: 13083-870 Campinas (SP) - Brasil \\ Tel: (55 19) 3289-1562 - springer_kalina@yahoo.com.br
}

\begin{abstract}
RESUMO
Aparentemente definir-se Natureza é fácil. Contudo, não teria a idéia de Natureza um aspecto polissêmico? Não seria seu conceito, apenas produto de contextos históricos, produto de nossa história? Especificamente para o conhecimento geográfico o entendimento do que é Natureza é de primordial importância, uma vez que ela constitui-se em um dos conceitos fundantes de nossa ciência. Ao compreender como as concepções de natureza influenciam o pensar, o agir sobre a natureza e sobre a própria construção do conhecimento, é possível inferir como as paisagens e os espaços são organizados, (re)estruturados, (re)interpretados e (re)construídos. Dentro deste contexto, considera-se Natureza como um conceito chave dentro de cada cultura (sociedade), sendo possível, através dele, melhor compreender as relações sociais e sócio-naturais que as caracterizam.
\end{abstract}

Palavras-chave: Concepções de natureza, Geografia, epistemologia.

\begin{abstract}
Normally to define Nature is easy. Has got the Nature notion a polysemic aspect? Isn't is concept, just a product of particular historical contexts? It would not be its concept, only product of historical contexts, product of our history? Specifically for the geographic knowledge the agreement of what it is Nature is of primordial importance, a time that it consists in one of the fundantes concepts of our science. When understanding as the conceptions of nature they influence thinking, acting on the nature and on the proper construction of the knowledge, it is possible to infer as the landscapes and the spaces are organized, (reverse speed) structuralized, interpreted and constructed. Inside of this context, Nature is considered as a concept key inside of each culture (society), being possible, through it, better to understand the social and partner-natural relations characterize that them.
\end{abstract}

Key words: Nature's concept, Geography, epistemology

\section{RÉSUMÉ}

Apparemment se définir Nature est facile. Néanmoins, n'aurait pas l'idée de Nature un aspect multiple ? Ce ne serait pas son concept, seulement produit de contextes historiques, produit de notre histoire ? Spécifiquement pour la connaissance géographique l'accord dont c'est Nature est de primordiale importance, vu qu'elle se constitue dans un des concepts fundantes de notre science. À la compréhension comme les conceptions de ils nature influencent la pensée, l'action sur la nature et sur la construction elle-même de la connaissance, c'est possible d'inférer comme les paysages et les espaces sont organisés, (poupe) structurés, (poupe) interprétés et (poupe) construits. À l'intérieur de ce contexte, se considère Nature comme un concept clé à l'intérieur de chaque culture (société), en étant possible, à travers lui, mieux comprendre les relations sociales et les sócio-natureles qui les caractérisent.

Mots-clés: Conceptions de nature, Géographie, epistemologie.

\section{INTRODUÇÃO}

Inserida em um contexto de rápidas e constantes transformações a humanidade encontra-se submersa em uma complicada e complexa teia de eventos sociais e ambientais. Particularmente, na Geografia, estas transformações verificam-se com muita intensidade, já que, o objeto de estudo de nossa ciência é formada tanto pela dimensão social, como natural. Partindo-se deste pensamento, independente da abordagem dada ao estudo, seja a natureza interpretada como natural; artificial; ou até mesmo social; ela esta sempre presente na base deste espaço e desta sociedade presente neste espaço. Assim, a Natureza se encontra subjacente à maioria das pesquisas em Geografia.

Posto isso, algumas reflexões podem ser realizadas: O que o Geógrafo entende por Natureza? As concepções de Natureza divergem nas várias abordagens geográficas? Ou, ainda qual a relação sociedade / Natureza que as concepções de Natureza utilizadas nas pesquisas legitimam? Qual o papel consolidado pela Geografia dentro das pesquisas acerca da Natureza? E, mais especificamente o que é Natureza? Quais as origens destas concepções? Qual a relação entre estas concepções, suas justificativas e os objetivos das pesquisas geográficas? O presente artigo tem como objetivo responder a algumas destas indagações. 


\section{APORTE METODOLÓGICO E O RECORTE TEÓRICO}

De acordo com Lakatos \& Marconi (1991, p.27) “analisar significa estudar, decompor, dissecar, dividir, interpretar. A análise de um texto refere-se ao processo de conhecimento de determinada realidade e implica o exame sistemático dos elementos [...]"; segundo estes autores é a análise que vai permitir observar os componentes de um conjunto, perceber suas possíveis relações, ou seja, passar de uma idéia-chave para um conjunto de idéias mais especificas, passar à generalização e, finalmente, à crítica. "Portanto, a primeira parte compreende a decomposição dos elementos essenciais e sua classificação, isto é, verificação dos componentes de um conjunto e suas possíveis relações. Dito de outra forma passa-se de uma idéia-chave geral para um conjunto de idéias mais precisas". (LAKATOS \& MARCONI, 1991, p.28)

Esta análise também leva em consideração as idéias dos autores, o conteúdo das obras e as mensagens transmitidas e procura associar as idéias pelo autor lido com outras formas de conhecimento investigando aspectos como a coerência interna e a validade dos argumentos empregados no texto. Para isso, alguns princípios gerais sobre análise e interpretação de textos devem ser ponderados, entre eles a (des)construção do texto, recompondo o plano geral de sua escrita: itens, sub-itens e a articulação entre esses. Só então se poderão selecionar os tópicos mais importantes para serem reagrupados e analisados.

Além de se destacar os temas tratados, é necessário estar atento também ao que falta ser tratado nele. $\mathrm{O}$ autor alerta que o silêncio pode ser revelador. Feito isso então se pode partir para a escolha de aspectos relevantes à compreensão do texto, para serem interpretados. Segundo Lalande (1996, p.221) o ato de criticar significa: "o exame crítico de um principio ou de um fato, a fim de produzir sobre ele um juízo de apreciação". Assim, analisar e interpretar textos criticamente é uma tarefa difícil e requer daquele que analisa juízo crítico e um bom quadro teórico. Alem disso, é preciso ponderar para que, o exercício de uma crítica negativa, não deponha mais contra quem a fez do que às eventuais falhas que o autor lido possa ter cometido.

Como material de análise, optou-se pelas dissertações produzidas no PPGG-UFPR, desde sua fundação, com a primeira dissertação defendida em 2000 até 2006. Para a seleção deste material identificaram-se as pesquisas cujas temáticas relacionam-se à idéia de Natureza. A partir desta seleção teve-se a delimitação do material de análise que se constituiu em 65 dissertações, o equivalente a 64,35\% das dissertações produzidas pelo PPGG-UFPR até o ano de 2006.

Com base na fundamentação teórica a respeito das diversas concepções de Natureza procuramos identificar os seguintes itens: a) Existência ou não da definição de Natureza que norteia o trabalho; b) Qual a referência mais utilizada; c) Qual posicionamento filosófico do autor. Ao não se encontrar definição clara acerca da concepção de Natureza (ou ainda um posicionamento filosófico claro), esta foi identificada partindo-se da concepção filosófica que norteou a dissertação. Esta identificação foi realizada por meio da leitura e análise, observando-se algumas características como: os 'termos' utilizados na pesquisa, o método cartesiano de análise, aplicações metodológicas, os métodos e as técnicas, e a estrutura da pesquisa.

\section{AS CONCEPÇÕES DE NATUREZA NO MUNDO OCIDENTAL: BREVES CONSIDERAÇÕES}

É absolutamente indubitável que qualquer conhecimento se forma numa cultura dada, a partir de um stock de noções, de crenças, de idéias, de um vocabulário [...] (MORIN, 1996, p.26).

Nosso texto começa com uma indagação que, aparentemente seria fácil de responder: $\mathrm{O}$ que é Natureza? Segundo Santos \& Cigolini (2007) a idéia de Natureza costuma ser tão vaga quanto controversa, ao mesmo tempo em que adquire considerável importância ao se admitir que, de uma forma ou de outra, o que se concebe como Natureza está subjacente a tudo que se faz e se pensa sobre meio ambiente.

Segundo Whitehead (1993) seria possível pensar na Natureza conjuntamente com o pensamento sobre o fato de a Natureza ser alvo do pensamento. Neste caso, se pensaria 'heterogeneamente' sobre 
a Natureza. Todavia o interesse da ciência natural estaria voltado exclusivamente para os pensamentos 'homogêneos' sobre a Natureza, ou seja, para aquela Natureza que independe do pensamento, e existe a priori dele. Para Carvalho (1990) na linguagem cotidiana usamos as expressões 'natural' e / ou 'Natureza' como contraponto àquilo que seria artificial. Assim, tudo que seria artificial não seria natural. Mas o que é artificial e o que é natural? Para o autor o que levará a ressaltar diferenças ou semelhanças, serão as convenções que se adotam para satisfazer às conveniências.

Já, para Durkheim (2001) o homem não poderia viver entre as coisas sem formular idéias a respeito delas. Para além disso, o autor salienta ainda que estas idéias regulariam toda a conduta humana. Merleau-Ponty (2000) considera a Natureza como um objeto enigmático, um objeto que não é inteiramente objeto. Afirma o autor que existe Natureza por toda a parte que há vida com sentido, porém sem pensamento. Ou seja, a Natureza seria tudo o que tem sentido, sem que esse sentido seja estabelecido pelo pensamento.

Com o objetivo de caracterizar os variados modos de conceber a Natureza ao longo do tempo (sociedade ocidental) entrelaçaram-se fatos históricos, conhecimento filosófico, conhecimento científico e concepção de Natureza. Identificaram-se alguns marcos (históricos, teóricos e epistemológicos) definidores de períodos e cuja caracterização demonstra ao longo do texto a relação intrínseca e indissociável entre história, filosofia, conhecimento científico e concepção de Natureza. Foram criadas quatro tipologias: a) Phisis na Grécia Antiga; b) Natureza divinizada; c) a Natureza mecânica e racional e d) novas teorias: que Natureza é essa?

Mitologia e a Phisis na Grécia Antiga. Para Montibelles Filho (2004) o primeiro conceito de 'Natureza' é o das culturas arcaicas, nas quais o homem é, antes de tudo, parte do grande organismo da 'Natureza', concebido como totalidade divina. Observa-se, portanto um conceito includente de 'Natureza', no qual aparece uma relação umbilical entre esta e o homem. Assim, segundo Henrique (2004) neste período o conhecimento sobre a 'Natureza' era fruto da imaginação e contemplação, principalmente pelos relatos heróicos dos 'aventureiros' atrelando a idéia de 'Natureza' à concepção de mito . Cita-se como exemplo um trecho do poema de Homero :

O navio foi levado por um vento favorável, através do mar alto, a barlavento de Creta, mas Zeus resolvera destruí-lo. Depois que tínhamos deixado Creta para traz e que não se via mais terra, apenas mar e céu, o filho de Cronos levou uma nuvem escura sob o navio e o mar escureceu sob ela. Em seguida Zeus trovejou e relampejou ao mesmo tempo e atingiu o navio com o raio. Todo o madeirame tremeu e o lugar ficou cheio de enxofre. Todos que estavam a bordo foram lançados ao mar e levados pelas ondas escuras: foi vontade de Zeus que eles nunca mais vissem sua pátria. Fique em más condições, mas o próprio Zeus pôs o mastro do navio em minhas mãos, uma enorme haste, para salvar-me novamente da morte. Com os braços passados em torno deles, foi empurrado pelos ventos malditos. (HOMERO, s.n, p.152)

Penedos (1984) relata que, o homem arcaico não via nestes mitos quaisquer fábulas ou estórias maravilhosas, bem pelo contrário, aceitava-os como reais, orientando suas atitudes de acordo com estas estórias. Para o autor, atividades como a construção de uma casa e a pesca (para citar alguns exemplos) eram atos praticados copiando-se os gestos das divindades, os quais eram conservados através de narrativas orais, que posteriormente, com o advento da escrita seriam registrados.

Morin (1977) infere que este universo mitológico é tido também como 'anismista' estando povoado por gênios e espíritos concebidos de modo 'antropozoomórfico', isto é, feitos do mesmo tecido que o universo. Esta visão 'encantada' reconhecia mitologicamente a presença da generatividade dos seres animados e animadores.

Já, nos séculos VII e V aC as transformações ocorridas na Grécia Antiga proporcionaram o nascimento e a institucionalização da filosofia. Inicialmente, estes filósofos dedicaram-se a um conjunto de indagações: o que é o ser? O que é o mundo e qual sua origem? Qual a origem da phisis e quais as causas de sua transformação? Neste sentido, o tema principal de suas obras era a phisis correntemente traduzida pela palavra 'Natureza': era a cosmologia.

Mercator - volume 9, número 18, 2010: jan./abr. 
Entretanto, a phisis pré-socrática em muito se distancia da concepção atual de Natureza. Ao explicar a phisis, os pré-socráticos não faziam distinção do que hoje entendemos por Natureza e por homem. Assim, a phisis era compreendida como um princípio único que originava e ligava todas as coisas. Penedos (1984) salienta que o universo era animado por um fluxo único que alem de interligar todas as coisas, estas participam juntas de um único processo evolutivo. A phisis era uma entidade que significava gênesis, origem e substrato de todas as coisas. Era esta entidade que dava origem a todos os seres, sendo imortal, fator este que a diferenciava das coisas físicas que eram mortais. Para Chauí (2001):

[...] a realidade é a Natureza e dela fazem parte os humanos e as instituições humanas. Por sua participação na Natureza, os humanos podem conhecê-la, pois são feitos dos mesmos elementos que ela e participam da mesma inteligência que a habita e dirige... Desta forma, o intelecto humano conhece a inteligibilidade do mundo, alcança a racionalidade do real e pode pensar a realidade porque nós e ela somos feitos da mesma maneira, com os mesmos elementos e com a mesma inteligência. (CHAUÍ, 2001, p.113)

Período Medieval e a Natureza Divinizada. Com o desaparecimento da 'polis' grega e a difusão do pensamento cristão, tem-se gradativamente a substituição a do pensamento greco-romano pelos ensinamentos bíblicos preconizados Igreja Católica Apostólica Romana. Segundo Ponting (1995) a concepção de Natureza preconizada por Aristóteles na Grécia Antiga serviria como fundamentação para a 'ciência' e a cosmologia da Idade Média . Neste momento dentre vários teólogos importantes mencionam-se as idéias de Santo Agostinho (354-430) e Tomás de Aquino (1225 - 1274). Para Santo Agostinho a Natureza se constituía em obra divina, separada do mundo dos homens. Ela pertenceria a um segundo plano, superior àquele onde viviam os homens:

As iguarias que me apresentavam a mim, faminto da vossa graça, eram em vez de Vós, o Sol e a Lua, lindas obras vossas, mas enfim obras vossas e nunca Vós mesmo. Aquelas nem sequer são as primeiras da criação. Com efeito, as vossas criaturas espirituais são superiores às corpóreas, ainda que estas se apresentem brilhantes e se movam pelo céu. (AGOSTINHO, 1973, p.61)

Segundo Aquino (1998) esta dissociação entre o que é divino e o homem reside no fato de o homem ter uma dupla Natureza: por sua alma, pertence à série dos seres imateriais, mas não é uma inteligência pura, pois se encontra essencialmente ligado a um corpo. Assim, percebe-se a ruptura com o pensamento greco-romano: o homem não se insere mais como um elemento num conjunto. Ele não mais possui o seu lugar como as coisas têm o seu lugar, é transcendente em relação ao mundo físico, não pertence à Natureza. Além disso, Aquino (1998) afirmava que as criaturas não existem por si mesmas, e sim devido a uma outra realidade. Para Aquino (1998) apenas em Deus haveria identidade entre essência e existência, ou seja, somente Deus existiria por si, sendo criador de todas as coisas e fundamento de suas existências.

Neste paradigma, nada poderia ocorrer senão pelas mãos divinas que traçavam e legislavam sobre as coisas. Os ciclos naturais, o movimento, as mudanças em todo o meio natural seriam provocadas intencionalmente por uma inteligência superior que ordenava e regulava a finalidade de todas as coisas. De acordo com Pepper (1996) essa perfeição divina era representada pela cosmologia medieval, onde o universo perfeito criado por Deus para servir ao homem, onde as estrelas descreviam movimentos perfeitos e o cosmos seria sólido, estacionário, finito e esférico. Assim, acreditava-se que, o movimento dos astros era circular e geometricamente perfeito, reproduzindo a Natureza de Deus e constituindo-se na própria essência divina . Como 'obra do criador' foi dada por Deus ao homem, para que ele dominasse e tirasse dela tudo o que precisasse para viver. De acordo com o capítulo I do livro Gênesis:

Deus criou o homem à sua imagem, [...] e Deus os abençoou e lhes disse: sede fecundos e multiplicaivos, enchei e subjugai a Terra. Dominai sobre os peixes e sobre tudo que vive e se move sobre a Terra. (BIBLIA, 1995, p.23) 
Por outro lado, como obra divina, ela servia também aos desígnios divinos, sendo utilizada por Deus como instrumento para castigar os homens. Neste contexto Henrique (2004) salienta que as catástrofes naturais eram atribuídas ao fato de Deus estar desgostoso com os homens e também com a vida que os pecadores levavam, sendo assim o estopim dos 'descontroles' na Natureza. Esta idéia pode ser exemplificada no Êxodo - Capítulo VII, onde Deus mostra sua fúria contra o 'coração endurecido' do Faraó (rei do Egito) que não queria deixar o povo partir. E, Deus ameaça: “[...] Os peixes que estão no rio morrerão, e o rio ficará tão poluído que os egípcios sentirão nojo de beber a água do Nilo". (BIBLIA, 1995, p.66).

Rompe-se aqui com a idéia grega de uma participação direta e harmoniosa entre nosso Ser e o mundo. A Natureza é vista, portanto como exterior ao homem, como obra divina é utilizada por ele ora para castigar ora para beneficiar os homens. Assim, estabeleceu-se uma relação ora de medo, ora de adoração para com Natureza sendo a Bíblia, fonte de entendimento desta Natureza.

Natureza mecânica e racional. A transição entre as concepções de mundo predominantes durante a Idade Média e as novas teorias da Idade Moderna, coexiste a acontecimentos como: renascimento cultural, grandes navegações, os descobrimentos e consolidação do capitalismo como principal modo de produção. Neste contexto, tem-se uma série de transformações nas relações entre os homens e entre estes e a Natureza cuja estrutura é caracterizada ideologicamente por uma nova concepção de universo, de Natureza e conseqüentemente de ciência.

A burguesia e o modo de produção que então se consolidava, em alguns casos financiaram a nova ciência e conseqüente influenciaram o desenvolvimento das concepções que ajudaram a formar . Segundo Vesentini (1989) a 'ciência moderna' torna-se base para o desenvolvimento da produção capitalista. Conforme Deus (1979) a nova percepção de Natureza passa a atender aos interesses do modo de produção europeu. Segundo Vesentini (1989) as concepções capitalistas de trabalho, sociedade e Natureza se articulam com a definição de um conhecimento 'objetivo' e 'racional'. Neste contexto a realidade gradualmente se transforma em um sistema racional de mecanismos físicos cuja estrutura profunda e invisível é matemática.

Em 1687 Isaac Newton (1642 - 1727) desenvolveu a lei da gravitação universal utilizando a matemática para a compreensão desta nova forma de ver o universo e conseqüentemente a Natureza. O universo newtoniano era formado por milhões de átomos sólidos que seguiam as leis do movimento, que, subordinadas à gravidade, ordenava tudo de forma constante e imutável. Neste sistema mundo, as de proposições matemáticas deduziriam também o movimento dos planetas, dos cometas, da Lua e do mar. Assim, tudo o que acontecia no universo tinha causa definida, gerando também um efeito definido. E, cada detalhe do movimento de um objeto seria matematicamente previsível.

Na concepção de Newton a Natureza era absoluta, imutável, sem criatividade, e composta por partículas indivisíveis que seguiam as leis do movimento mecânico. Para o autor a utilização da linguagem matemática permitiria ao homem o conhecimento, a explicação e a previsão de todo o movimento que ocorre na Natureza. Newton (1990) utilizando os preceitos mecanicistas postulou que os movimentos que haviam no universo eram semelhantes à sincronia existente no interior de uma grande máquina . Desta forma Bohm (1980) afirma que Newton, ao consolidar a concepção mecânica de universo linear e sincrônico, acabou direcionando também o pensamento e a percepção de todo o meio natural atual.

Esse mundo máquina, teve também como idealizador Francis Bacon (1561 - 1626) que, buscava uma ciência que pudesse penetrar nos mistérios da Natureza. Bacon (1984) escreve que a 'Natureza mecanizada' podia ser controlada se, pela ciência compreendida fosse. Já, René Descarte (1596 - 1650) buscou o desencantamento do homem através da separação entre corpo e alma. Para Descartes (1987) a separação entre corpo e alma liberta o homem da simples admiração ou medo para a dominação do mundo e da Natureza e a produção de conhecimento livre de princípios e verdades pré-existentes. Do mesmo modo, proporcionaria a superação dos instintos animais, das emoções e das paixões pelo intelecto e racionalidade. 
Tem-se então a partir de René Descarte a consolidação da visão científica antropocêntrica a partir da observação de que 'só o homem combina, ao mesmo tempo, matéria e intelecto'; e a racionalidade era concebida como essência da verdade. Lenoble (1969) explica que para Descartes o universo era como um mecanismo organizado e sincrônico, assim como um relógio. E que, cada peça desta engrenagem, exercia uma função determinada. Assim, Vesentini (1989) salienta que o universo vai sendo concebido à imagem de uma máquina, e de uma Natureza instrumental: as partes são vistas separadamente, de forma analítica, o que importa é a funcionalidade de cada uma delas em relação ao maquinismo geral.

Para Lenoble (1969), mecanizada a Natureza torna-se uma simples possibilidade de exploração técnica, concepção explorada ao máximo pela indústria nascente. De acordo com Araújo (2003) esta nova ciência era essencialmente mecânica, baseava-se na experiência, na matemática e procurava relações mensuráveis e calculáveis. Para Henrique (2004) neste momento o homem não só toma consciência de sua força modificadora da Natureza, bem como dissocia desta ação o pecado ou a audácia de imitar o Criador. $\mathrm{O}$ homem como inventor, experimentador, curioso, inquieto, ativo na sua habilidade manual, cria formas para dar um novo sentido à Natureza.

Novas Teorias: Que Natureza é Essa? O período que compreende desde fins do século XIX até os dias atuais foi marcado por intensas transformações especificamente dentro da física, . Entretanto, segundo Capra (1996), foi com a Teoria da Relatividade e a Teoria Quântica de Albert Einstein (1879 - 1955) que surgiram novas formas de compreensão do universo e conseqüentemente da Natureza. O mundo subatômico que antes era sólido, agora se transformou em energia indivisível: não mais formado por probabilidade de coisas (uma vez que não existem coisas no mundo subatômico) e sim probabilidades de interconexões. Para Capra:

[...] as inter-relações e interações entre as partes e as partes com o todo são mais importantes do que as próprias partes. Há movimento mas não existem, em última análise objetos moventes, há atividade, mas não existem atores, não há dançarinos, somente a dança. (CAPRA, 1982, p.86)

Assim, por meio do Principio da Relatividade / Probabilidade (nunca previsibilidade) surge uma nova lógica: descontínua, ocasional e interconectada. No mundo subatômico, aquilo que imaginávamos como sólido dissolvia-se em energia e era integrado por interconectividade ao maior elemento do universo.

[...] as partículas subatômicas não são 'coisas', mas interconexão entre as 'coisas' e essas 'coisas' por sua vez são interconexões entre outras 'coisas' e assim por diante. Na teoria quântica não lidamos com 'coisas' lidamos sempre com interconexões. (CAPRA, 1982, p.75)

Surge o indeterminismo, a desordem e a incerteza. Para Morin (1977) a desordem é orgânica e necessariamente parte da phisis, compondo a ordem universal, sendo possível a idéia de um universo que constitui sua ordem e sua organização na turbulência, na instabilidade, no desvio, na improvisação e na dissipação energética. A este respeito Prigogine (1996) afirma ainda que quando ocorre desordem em um fluxo sistêmico, não há necessariamente uma exclusão, e sim uma integração. Desta forma, a desorganização de um sistema poderia trazer um novo patamar de organização da totalidade em uma nova ordem e o conceito de desordem não é mais compreendido como um conceito de oposição à ordem.

Recordo as discussões com Bohr que se estendiam por horas a fio, até altas horas da noite, e terminavam quase em desespero, e, quando no fim da discussão, eu saia sozinho para um passeio no parque vizinho, repetia para mim, uma vez ou outra, a pergunta: será mesmo a Natureza tão absurda quanto nos parece nesses experimentos atômicos? (HEISENBERG apud CAPRA, 1982, p.71).

Desta forma, a exploração do mundo atômico e subatômico colocou os cientistas em contato com uma estranha e inesperada realidade, que desencadeou uma ruptura com a concepção de ciên- 
cia objetiva e neutra, adjetivos até então utilizados para caracterizar todo o conhecimento científico. Neste contexto a teoria de Einstein trouxe conseqüências diretas para todo o conhecimento cientifico que, na busca por novas epistemologias, urgiria por uma reestruturação cientifica. Para tanto, Capra (1982) escreve que seriam necessárias profundas mudanças nos conceitos de espaço, tempo, matéria, objeto, causa e efeito, conceitos esses fundamentais para entender o modo como se vivencia o mundo.

Assim, estas teorias inovadoras trariam incertezas e inseguranças. Seria possível conceber que, no mundo subatômico não havia previsibilidade? Seria possível ao mesmo tempo observar o fenômeno e também fluir nele? Haveria uma seqüência lógica para as observações? Contudo, esta mudança de 'objetos' para 'relações' traria também implicações não só para as ciências aplicadas, mas também para aqueles pensadores que se preocupam em quais as implicações filosóficas que este novo pensar teria na compreensão da realidade e da Natureza.

Outro insight na física atômica foi a compreensão de que os fenômenos observados são determinados em grande medida pela consciência humana. Capra (1982) infere que os fenômenos observados na física quântica só podem ser entendidos como correlações entre vários processos de observação e medição estando o fim desta cadeia sempre na consciência daquele que observa o fenômeno. Assim, a simples decisão consciente de observar um fenômeno, por si só poderia determinar algumas propriedades deste fenômeno, ou seja, a resposta é dada conforme o que se é observado e qual o questionamento feito. Desta forma um fenômeno, mesmo externo a mim, não possuiria propriedades objetivas independentes de minha consciência. Capra (1982) relata que na física atômica, não poderia mais ser mantida a divisão existente na física newtoniana entre matéria e consciência humana. Para o autor se falaria da Natureza, sem ao mesmo tempo, falar-se de nós mesmos.

Este novo insight traria mais um desafio para a ciência como um todo. Acorda-se para compreensão de que a escolha dos fenômenos a serem estudados pelos cientistas, não estariam isento de valores. Eles relacionam-se intimamente com a consciência humana, cujos pensamentos e valores poderiam condicionar os resultados científicos. Capra (1982) infere que dentro desta nova concepção de mundo, surgem novas teorias para explicar o mundo e a Natureza. Um exemplo citado por Capra (1982) seria o pensamento taoísta que entende o universo como uma teia dinâmica de eventos inter-relacionados cuja nenhuma das propriedades de qualquer parte desta teia é fundamental: todas decorrem das propriedades das outras partes. Nesta visão a estrutura da teia é determinada pela inter-relação entre as propriedades das partes.

Para Ponting (1995) o pensamento taoísta enfatiza a idéia de equilíbrio de forças onde a sociedade e os indivíduos deveriam viver de forma equilibrada e harmoniosa com o mundo natural. O centro desta filosofia não seria o domínio sobre o mundo, mas a idéia de compaixão universal. De certa forma, este novo olhar representaria uma nova aliança com a Natureza. E, de acordo com Stengers (1990) esta nova aliança seria uma escuta poética da Natureza, reintegrando o homem no universo que ele observa.

\section{A NATUREZA NA GEOGRAFIA PRODUZIDA NO PPGG-UFPR (1999 - 2006): ALGUMAS CONSIDERAÇÕES}

[...] conceitos de uma disciplina são freqüentemente apenas metáforas nas outras, por mais vizinhas que se encontrem. Metáforas são flashes isolados, não se dão em sistemas e não permitam teorizações. (p.70) [...] à Geografia que cabe elaborar seus próprios conceitos, antes de tentar emprestar formulações de outros campos. (SANTOS, 1997, p. 71)

As análises realizadas nas dissertações produzidas no PPGG-UFPR mostraram que a discussão acerca dos conceitos de Natureza raramente acontece. Outros conceitos são discutidos, tais 
como território, paisagem, lugar, abordagem sistêmica, bacia hidrográfica, EIA / RIMA, impacto ambiental, elementos ambientais (solos, estrutura geológica, vertentes,...), fragilidade ambiental, urbanização, legislação ambiental, entre outros. Isto pode ser claramente exemplificada em trecho escrito por SANTOS (2005):

As referências bibliográficas comentadas a seguir têm a intenção de focalizar as bases conceituais e teóricas que estruturam este trabalho, enfatizando a importância dos estudos ambientais em bacias hidrográficas, os fundamentos de análise da fragilidade ambiental, bem como os elementos básicos para o seu reconhecimento, ou seja, o estudo dos solos e dos processos geomorfológicos. O ambiente urbano também foi considerado, dado a sua expressão areal na bacia em estudo. (SANTOS, 2005, p. 15)

Discussões a cerca da natureza. Dentre os trabalhos que, mesmo de forma sucinta, traziam uma discussão acerca do conceito de Natureza, em boa parte deles, estas definições estavam soltas, desconexas ou ainda descontextualizadas no corpo do texto, ou seja, não apresentavam ligação ou até mesmo coerência aparecendo deslocadas e fora de contexto. Como exemplo cita-se Schellmann (2005), que apesar de algumas tentativas de conceituar Natureza, não se percebeu a preocupação de efetivamente tecer uma discussão mais sólida sobre o assunto, por menor que fosse essa discussão.

Schellmann (2005, p. 130) cita Sauer (2001, p.25), "É este o sentido que a sociedade vem atribuindo à paisagem por meio da valorização estética da Natureza"; cita-se também Tuan (1983, p. 97) "A Natureza, portanto, torna-se um espaço, do qual teremos uma extensão conceitual dos espaços familiar e cotidiano dados pela experiência direta do homem [...]". Em outro momento, em meio a discussão sobre a metodologia e as concepções filosóficas do trabalho a autora faz uma breve inferência à concepção de Natureza.

O objeto de estudo somado com a análise interpretativa forma um sistema, sendo este atribuído a estas correlações objetivas ou não, da qual temos um conjunto de correspondências vividas. A transição de um pensamento simbólico para este conjunto, quando temos a percepção do ser espacial de forma singular (Merleau - Ponty, 1999, p.274) . [...] A Natureza como concepção e idéia, apreendida no processo de conhecer, tendo o homem como pensante de tal processo. [...] A Natureza vai além destas concepções, ela é difusa e com estímulos conflitantes e poderosos. [...] (p.07). A experiência é um termo da qual abrange as mais diferentes maneiras que uma pessoa concebe e constrói a sua realidade vivida diante das diversas situações (TUAN, 1983, p. 09) (SCHELLMANN, 2005, p. 07)

Neste contexto, verificou-se que, dentre as 65 dissertações analisadas apenas duas delas trazem o conceito de Natureza e o discutem de forma bem mais contextualizada, fazendo a menção de que, este não é um conceito, pronto, objetivo e estático: Rigon (2005) e Hassler (2006). O principal legado destes dois trabalhos, está na compreensão e consequentemente exposição no trabalho de que, o conceito de Natureza não é um conceito pronto, estático, ele se transformam no decorrer do tempo e conforme a concepção de mundo de cada autor, podendo assumir variadas conotações, dependendo do viés pelo qual é analisada, sendo por isso importante identificá-las e defini-las de acordo com os objetivos ao qual o trabalho se propõe. Além de contextualizada ao trabalho, Rigon (2005) faz menção a alguns autores, cujas idéias e concepções de Natureza, apresentam-se a seguir:

As questões que vem sendo debatidas acerca da relação sociedade Natureza apontam a necessidade de esclarecimento sobre alguns conceitos. Segundo Suertegaray (2001, p. 114) “determinadas correntes do pensamento geográfico entendem Natureza como algo externo ao homem, um conjunto de todas as coisas produzidas sem a intencionalidade humana [...]”.(RIGON, 2005, p, 23)

Segundo Casseti (2001, p.146) "a concepção de uma Natureza externalizada, de base mecanicista, foi recuperada no Iluminismo para atender as especulações do sistema de produção [...]”.(RIGON, 2005, $\mathrm{p}, 23)$ 
Smith citado por Cidade (2001, p.101) embora acreditando na prioridade social da Natureza, tem abordado a separação analítica entre sociedade e Natureza como reflexo da lógica interna do capitalismo. (RIGON, 2005, p.24)

Referência mais utilizada. O autor mais utilizado para conceituar e ou discutir a respeito do conceito de Natureza foi Carlos Walter Porto Gonçalves. Dente vários exemplos a serem mencionados, cita-se o trabalho desenvolvido por Saraiva (2004); este autor cita Gonçalves (1996, p.25), "[...] em nossa sociedade, a Natureza pode ser considerada como tudo aquilo que se opõe a cultura" (SARAIVA, 2004, p.10). Este mesmo trecho escrito por Gonçalves aparece freqüentemente em varias dissertações.

Encontraram-se ainda pesquisas, nas quais as idéias dos autores referenciados poderiam ser mais bem detalhadas a fim de simplificar o entendimento do autor e do próprio leitor. A esse respeito cita-se como exemplo a dissertação de Santos (2001). Com o objetivo de conceituar Natureza, Santos (2001) se fundamenta e se apropria da definição de Milton Santos: “[...] a Natureza é hoje um valor, ela não é natural no processo histórico, ela é social [...] se são naturais não são recursos, e para serem recursos, têm que ser sociais" Santos (2000) .

Parece que, Milton Santos, neste pensamento tenta colocar que apesar de hoje a Natureza ser concebida como um valor, esta somente se torna recurso quando apropriada pelo homem em seu processo histórico, sendo assim ela não é natural e sim social, uma vez que apropriada. E, se assim não o fosse ela não seria natural e não seria recurso.

Contudo, a interpretação que Santos (2001) faz do pensamento de Milton Santos aparece de forma, um tanto quanto nebulosa no que se refere ao seu entendimento. Assim, Santos (2001, p.18) se reporta ao pensamento de Milton Santos (2000) com a seguinte afirmação: "Essa afirmação considera que tudo na Natureza é recurso, embora ela apareça como natural apenas de forma isolada, todavia faz sobressair o caráter social da Natureza [...]”.

Filosofia, Natureza e Geografia. Como já foi mencionado anteriormente, a maioria das produções analisadas não tiveram preocupação em analisar qual a corrente filosófica mais adequada ao seu trabalho. Contudo, partindo-se do pressuposto que toda a construção cientifica esta diretamente influenciada por posicionamentos filosóficos, principalmente àqueles de cunho mais aplicativo (como é o caso da grande maioria dos trabalhos analisados), evidencia-se a importância da reflexão filosófica. A respeito da importância das concepções filosóficas e suas conseqüências cita-se Mendonça (1989):

Regra básica exigida para a caracterização do conhecimento científico, o método científico, nada mais é que fruto da associação de concepções filosóficas à ciência. (MENDONÇA, 1989, p. 40)

Assim, a analise realizada mostra certo descomprometimento por parte dos Geógrafos do PPGG-UFPR para com a epistemologia de sua ciência e conseqüentemente para com a importância que a filosofia e seu entendimento têm na construção do saber. Pouquíssimas dissertações trazem uma explicação clara e objetiva quanto a posicionamento filosófico adotado. Dentre os raros exemplos, cita-se Schier (2003) que, abordando diferentes concepções de paisagem demonstra preocupação e posicionamento filosófico. Schier (2003, p.01) escreve que "A maioria destes conceitos [paisagem] se atrela, no fundo à determinadas abordagens filosóficas. Pode-se dizer que o conceito da paisagem foi originalmente ligado ao positivismo, na escola alemã...” E complementa:

Entre as atitudes relacionadas à paisagem exigem algumas que se identificam como um bem a ser preservado, representado a identidade de seus moradores, outros a tratam como recurso econômico e extrativo, outros vêem nela um desafio a ser modificado, ou ainda, a monumentalizam como um patrimônio, e outras avaliam com olhos estéticos e artísticos [...] Dentro de cada sociedade entre as sociedades, várias atitudes podem entrar em choque, pois percepções individuais e interesses econômicos por exemplo, se contrapõem pelas divergências de filosofias que as fundamentam. (SCHIER, 2003, p.02)

Mercator - volume 9, número 18, 2010: jan./abr. 
Entretanto, mesmo sem definição clara, sistemas filosóficos podem ser identificados através das características dos trabalhos, tais como: Quais 'termos' utilizam o autor? Quais eram seus objetivos principais? Quais os métodos e as técnicas utilizados? Qual seu referencial teórico? [...]. Tais características podem indicar em qual sistema filosófico a pesquisa esta inserida .

A leitura das dissertações indicou aproximação com três bases filosóficas principais. Primeiramente, e também em maior número encontram-se as pesquisas cujos pressupostos metodológicos aportam-se no positivismo e neopositivismo. Nesta perspectiva a Natureza é compreendida e trabalhada como uma entidade externa ao homem, servindo a este como fonte de recursos para o seu bem viver; e em função deste viver 'bem viver humano' ela deve ser protegida (às vezes de forma intocada) ou planejada quanto à sua utilização 'racional'; sendo a preocupações predominantes, questões relacionadas ao uso, planejamento e gestão. Neste sentido, estes estudos envolvem a caracterização e descrição, com objetivos altamente aplicáveis. Tem-se então a 'Natureza Racional'.

Em segundo aparecem as filosofias do significado cujos trabalhos geralmente objetivam entender como os indivíduos e ou grupos sociais percebem, interpretam e ou representam a 'Natureza' e ou este 'meio natural', ou ainda quais os elementos que fazem parte desta Natureza. Em sua maioria, estes trabalhos, preocupam-se com entendimento que o Homem tem da Natureza (ou do dito Natural): O que é a Natureza? E qual a relação entre esta e os grupos sociais?

Por último identifica-se a presença do materialismo dialético geralmente vinculado à perspectiva crítica . Neste caso, a Natureza geralmente aparece como recurso natural que serve de pano de fundo para outros temas; nestas pesquisas, mesmo quando a preocupação era a questão ambiental, o enfoque privilegiava a influência dos aspectos econômicos e ou políticos. Nesta perspectiva geográfica, ela torna-se um elemento dotado de valor econômico. Tem-se então que a Natureza, não mais seria um direito de todas e não mais se encontraria somente junto às classes mais baixas, agora, era preciso 'comprar' o 'verde'.

\section{CONSIDERAÇÕES FINAIS}

Há muitos anos os homens se empenham em 'decifrar os enigmas da Natureza', assim como os filósofos da Grécia Antiga já o faziam. Mas, sem dúvida, estas discussões alimentarão ainda muitos debates, uma vez que as 'verdades' até então ditas demonstram que, sua compreensão é produto de nossas idéias, de nossas concepções: abstrata, extremamente subjetiva e em permanente transformação.

Mostrou-se no decorrer do artigo que, cada período histórico foi marcado por um determinado posicionamento filosófico que dominante, direcionava a construção do conhecimento cientifico e conseqüentemente a concepção de Natureza e a forma de estudá-la ou entendê-la. Neste sentido, a Natureza não pode ser compreendida como algo dado, estático e objetivo. Essa diversidade de possibilidades é citada por Carvalho:

[...] as explicações e as definições, sejam do que for, inclusive de Natureza, jamais conseguira se dissociar da idéias e dos objetivos de mundo de quem explica ou define. Isto é para uma mesma pergunta: $O$ que é Natureza? Encontraremos muitas respostas dependendo do grupo humano, do tipo de sociedade, ou da classe social de quem responde. (CARVALHO, 1990, p.16)

Ela é subjetiva e não podemos considerá-la como verdade absoluta, externa ao homem; ela é criada por ele dentro de um contexto histórico, filosófico e geográfico especifico. Em tempo algum ela é o que é; a Natureza é o que os homens denominam que ela seja, uma vez que: conceito ou definição nada mais é do que uma construção humana. E a partir desta construção humana estabelecemos formas de concebê-la e de nos relacionarmos com ela.

$\mathrm{Na}$ atualidade, evidencia-se em diversas áreas do conhecimento a eclosão de novas teorias (Teoria da Auto - Organização , Teoria da Complexidade , Teoria das Estruturas Dissipativas ,...) 
referentes a estas novas visões de mundo que consequentemente trazem consigo novas concepções acerca da Natureza. E, em sentido inverso, tem-se também o retorno a antigas formas de conceber o mundo e a ciência.

Como exemplo, menciona-se a re-descoberta e re-valorização de modos de pensar alternativos à visão cartesiana, como o pensamento tradicional chinês do taoísmo, e do budismo. Estes passam por diferenciadas leituras de mundo, de Natureza, de corpo, das doenças, das idéias de saúde, das idéias de vida e morte. A exemplo a medicina tradicional chinesa, fundamentada numa idéia de organismo com a busca da harmonia entre o Ying e o Yang, possuindo técnicas e formas de encarar as doenças e a saúde, muito diferentes das quais preconizam a medicina tradicional ocidental.

Assim, nesta era de incertezas ficam algumas perguntas: A Natureza obedeceria à sincronicidade determinista ou apresentaria aleatoriedade na dinâmica de seus fluxos? Na Natureza a turbulência dos sistemas complexos seriam frutos da dinâmica ordem / desordem? Ou seriam frutos do acaso? Existiria uma dinâmica ordem /desordem? Como se definir o que seria uma turbulência natural e o que seria uma turbulência ocasionada? Seria possível prever e controlar os movimentos da Natureza, de forma precisa? Este é sem dúvida o objetivo máximo da ciência moderna, mas qual seria o objetivo o que ainda virá?

Partindo-se destas considerações, restam indagações: E a Geografia, como fica diante destes novos paradigmas? Como o geógrafo trabalha com o meio ambiente sem saber ao certo qual Natureza está defendendo? Será que estamos realmente contribuindo para a resolução dos problemas ambientais (premissa de grande parte dos trabalhos analisados), sem antes refletir que Natureza é essa? Como afirma Leff (2001, p.217):

Os problemas ambientais são, fundamentalmente, problemas do conhecimento. Daí podem ser derivadas fortes implicações para toda e qualquer política ambiental - que deve passar por uma política do conhecimento -, e também para a educação. Apreender a complexidade ambiental não constitui um problema de aprendizagens do meio, e sim de compreensão do conhecimento sobre o meio.

\section{REFERENCIAL BIBLIOGRÁFICO}

AGOSTINHO, Santo. Confissões. Editora: Abril (Coleção Os Pensadores), 1973.

AQUINO Tomás de. Seleção de Textos. Nova Cultural (Coleção os Pensadores), 1998.

ARAÚJO, Inês Lacerda. Introdução à filosofia da ciência. $3^{\circ}$ ed. Curitiba: Ed da UFPR, 2003.

ARISTOTELES. Tópicos dos argumentos sofísticos. São Paulo: Ed. Abril Cultural, 1978.

BACON, Francis. Novum Organum ou verdadeiras indicações acerca da interpretação da Natureza. $3^{\circ}$ ed. São Paulo: Abril Cultural, 1984. (Coleção os Pensadores).

BIBLIA. Bíblia Sagrada: estudando a palavra de Deus. São Paulo/ Rio de Janeiro: FTD/Vozes, 1995.

BOHM, David. A Totalidade e a ordem implicada. São Paulo: Cultrix, 1980

CAPRA, Fritjof. A teia da vida. São Paulo: Cultrix, 1996.

CAPRA, Fritjof. O ponto de mutação: a ciência, a sociedade e a cultura emergente. São Paulo: Cultrix, 1982.

CARVALHO, Marcos Bernardino de. O que é Natureza? São Paulo: Ed. Brasiliense, 1990.

CHAUÍ, Marilena. Convite à filosofia. 12ed, São Paulo: Ática, 2001.

CHUEH, Anderson Mendes. Análise do uso do solo e degradação ambiental na bacia hidrográfica do rio Pequeno - São José dos Pinhais /Pr, por meio do diagnóstico físico-conservacionista - dfc. Dissertação de Mestrado defendida pelo Programa de Pós-graduação em Geografia da UFPR, 2004.

DESCARTES, René. O discurso do método; As paixões da alma. São Paulo: Nova cultural, $4^{\text {a }}$ ed. 1987. DEUS, Jorge Dias. A crítica da ciência: sociologia e ideologia. Rio de Janeiro: Jorge Zahar, 1979.

DURKHEIM, Emile. As regras do método sociológico. 16ed. São Paulo: Comp. Editorial Nacional, 2001. HASSLER, Márcio Luis. Natureza na cidade: Uma abordagem a partir da percepção da população acerca 
do Jardim Botânico de Curitiba -PR. Dissertação de Mestrado defendida pelo Programa de Pós-graduação em Geografia da UFPR, 2006.

HENRIQUE, Wendel. O direito à Natureza na cidade: ideologias e práticas na história. Tese de Doutorado. Curso de Pós-graduação em Geografia - Instituto de Geociências e Ciências Exatas. Universidade Estadual de São Paulo. Rio Claro, 2004.

HOMERO. A Odisséia. São Paulo: Ed: escala, s.n.

LAKATOS, Eva Maria \& MARCONI, Marina de Andrade. Fundamentos de metodologia científica. $3^{\mathrm{a} e d .}$ São Paulo:Atlas, 1991.

LALANDE, André. Vocabulário técnico e crítico da filosofia. São Paulo: Martin Fontes, 1996.

LEFF, Enrique. Epistemologia ambiental. São Paulo: Cortez, 2001

LENOBLE, Robert. História da idéia de Natureza. Lisboa: Edições 70, 1969.

MENDONÇA, Francisco. Geografia Física: ciência humana? São Paulo: Contexto, 1989.

MERLEAU - PONTY, Maurice. A Natureza. São Paulo: Martins Fontes, 2000.

MONTIBELLER FILHO, Gilberto. O mito do desenvolvimento sustentável: meio ambiente e custos sociais no moderno sistema produtor de mercadorias. Florianópolis: Ed da UFSC, 2004.

MORIN, Edgar. O método: a Natureza da Natureza. Publicações Europa - América Ltda, 1977.

MORIN, Edgar. Problemas de uma epistemologia complexa. In: MORIN, Edgar (org) O problema epistemológico da complexidade. 2a ed. Portugal: Publicações Europa - América Ltda, 1996.

NEWTON, Isaac. Principia. São Paulo: Ed da USP / Nova Stella, 1990.

PENEDOS, Álvaro. Introdução aos pré-socráticos. Porto (Portugal): Ed. Rés, 1984.

PEPPER, David. Eco - socialism: from deep ecology to social justice. London, New York: Routledge, 1996. PONTING, Cleve. Uma história verde do mundo. Rio de Janeiro: Civilização Brasileira, 1995.

PRIGOGINE, Ilya. O fim das certezas: tempo, caos e as leis da Natureza. Ed da UNESP, 1996.

RIGON, Silvia do Amaral. Alimentação como forma de mediação da relação sociedade Natureza - um estudo de caso sobre a agricultura ecológica e o autoconsumo em Turvo -PR. Dissertação de Mestrado defendida pelo Programa de Pós-graduação em Geografia da UFPR, 2005.

SANTOS, Cássia dias Teixeira. Microbacia do rio Vila Formosa Curitiba - PR: Diagnóstico e zoneamento ambiental como subsídio ao planejamento. Dissertação de Mestrado defendida pelo Programa de Pós-graduação em Geografia da UFPR, 2001

SANTOS, Edelso dos. Mapeamento da fragilidade ambiental da bacia hidrográfica do rio Jirau município de Dois Vizinhos -Paraná. Dissertação de Mestrado defendida pelo Programa de Pós-graduação em Geografia da UFPR, 2005.

SANTOS, Irani; CIGOLONI, Adilar. Tudo que existe é: considerações sobre a idéia de Natureza em Milton Santos. In: SCHEIBE, Luiz Fernando; DORFMAN, Adriana (Org.). O Curso da Teoria: ensaios a partir d'a Natureza do Espaço. Florianópolis: Fundação José Boiteux, 2007.

SANTOS, Milton. A Natureza do espaço: técnica e tempo, razão e emoção. São Paulo: Hucitec, 1997.

SARAIVA, Fabiano. A unidade de paisagem da serra do Mar /Pr: Perspectiva de abordagem a partir do geossistema. Dissertação de Mestrado defendida na Pós-graduação em Geografia da UFPR, 2004.

SCHELLMANN, Karin. Do mito à realidade: Um olhar sobre a antártica através dos signos e das representações. Dissertação de Mestrado defendida pelo Programa de Pós-graduação em Geografia da UFPR, 2006.

SCHIER, Raul Alfredo. As concepções da paisagem no código florestal Dissertação de Mestrado defendida pelo Programa de Pós-graduação em Geografia da UFPR, 2003.

STENGERS, Isabelle. Quem tem medo da ciência? São Paulo: Siciliano, 1990.

VESENTINI, José Willian. Geografia, Natureza e Sociedade. São Paulo: Contexto, 1989.

WHITEHEAD, Alfred North. O conceito de Natureza. São Paulo: Martins Fontes, 1993.

Trabalho enviado em janeiro de 2010

Trabalho aceito em abril de 2010 